\begin{tabular}{|c|l|}
\hline Title & In situ observations of freezing processes of single micrometer-sized aqueous ammonium sulfate droplets in air \\
\hline Author(s) & Ishizaka, Shoji; Wada, Teruhide; Kitamura, Noboru \\
\hline Citation & $\begin{array}{l}\text { Chemical Physics Letters, 506(1-3), 117-121 } \\
\text { https://doi.org/10.1016/.cplett.2011.02.058 }\end{array}$ \\
\hline Issue Date & 2011-04-11 \\
\hline Doc URL & http://hdl.handle.net/2115/45254 \\
\hline Type & article(author version) \\
\hline File Information & CPL506-1-3_117-121.pdf \\
\hline
\end{tabular}

Instructions for use 


\section{In Situ Observations of Freezing Processes of Single Micrometer-sized Aqueous Ammonium Sulfate Droplets in Air}

Shoji Ishizaka a, b, c, *, Teruhide Wada ${ }^{\mathrm{a}}$, and Noboru Kitamura ${ }^{\mathrm{a}, \mathrm{b}, ~ *}$

a Department of Chemistry, Graduate School of Science, Hokkaido University, Sapporo 060-0810, Japan

${ }^{\mathrm{b}}$ Department of Chemical Sciences and Engineering, Graduate School of Sciences and Engineering, Hokkaido University, Sapporo 060-0810, Japan

${ }^{c}$ PRESTO-JST 4-1-8 Honcho Kawaguchi, Saitama 332-0012, Japan

*Corresponding authors. E-mail: shoji@sci.hokudai.ac.jp; kitamura@sci.hokudai.ac.jp.

Tel: 81-11-706-2710, Fax: 81-11-706-4630 


\begin{abstract}
The freezing processes of single micrometer-sized aqueous ammonium sulfate droplets levitated in air were observed by means of laser trapping and spectroscopy techniques. Single micrometer-sized aqueous ammonium sulfate droplets were levitated by radiation pressure in air. When a levitated droplet was cooled below $213 \mathrm{~K}$, a supercooled droplet was turned from the liquid to solid state. To the best of our knowledge, this is the first observation of the freezing processes of single micrometer-sized supercooled aqueous solution droplets in air by means of laser trapping and spectroscopy techniques.
\end{abstract}




\section{Introduction}

A laser trapping - microspectroscopy (absorption/emission/Raman) technique is the

fundamental basis for studying colloidal particles, since the technique can interrogate individual microparticles in solution as a function of a particle size [1]. As a typical example, we have hitherto reported the ion exchange processes in single resin particles in water, the electron/ion transfer processes across oil-droplet/water interfaces, a photoreaction in single oil-droplets in water, and so forth, and demonstrated that some of such chemical/physical phenomena depended on the sizes of the microparticles [2]. Thus, the optical trapping technique capable of choosing and manipulating an arbitrary-sized microparticle in solution is of primary importance for the study of colloidal particles. In contrast to colloidal particles, the number of the report on optical trapping of aerosol microparticles (i.e., microparticles in air or gas phase) is still limited [3-25], although aerosol plays key roles in both fundamental and applied research fields: atmospheric chemistry, chemical vapor deposition, nanoparticle synthesis, and so on.

Among various aerosol microparticles, in particular, aerosol water droplets in air are a very fascinating target of the study on laser trapping - microspectroscopy of single microparticles. If water droplets are cooled without a contact with solid surfaces, nucleation of ice can be avoided and water should take a metastable liquid state even below the freezing temperature of water. Therefore, supercooled aqueous solution 
droplets often exist in clouds and, play important roles in the earth's climate and atmospheric chemistry [26]. Freezing of supercooled aqueous solution droplets causes condensation of water vapor onto small ice crystals in clouds. When ice crystals grow and become too heavy to be suspended in air, they fall to the ground as rain or snow. Therefore, freezing of supercooled aqueous solution droplets is the fundamental process in the precipitation [27]. The presence of an inorganic salt such as $\left(\mathrm{NH}_{4}\right)_{2} \mathrm{SO}_{4}$ in water reduces the water vapor pressure and the freezing temperature of the droplets. Consequently, knowledge about salt concentration effects on the freezing temperature of supercooled aqueous solution droplets is of primary importance for modeling upper tropospheric clouds as well as for estimating global climate changes [28-31]. So far, experimental studies on liquid-to-solid phase transition of supercooled aqueous solution droplets have been conducted on the basis of aerosol flow tubes [30, 32-34], a droplet free-fall freezing tube [35, 36], electrostatic levitation [37-40], and acoustic levitation [41-43] techniques. Fundamental knowledge about phase transition of supercooled aqueous solution droplets has been accumulated in the past decades. Nonetheless, the effects of a solute concentration on the freezing temperature and kinetics of liquid-to-solid phase transition of micrometer-sized supercooled aqueous solution droplets are still controversial [35, 36, 44-46]. It is worth emphasizing that noncontact levitation of single micrometer-sized aqueous solution droplets in air can be achieved 
by a laser trapping technique and the methodology is a powerful means to study the freezing processes of supercooled aqueous solution droplets in air. A laser trapping technique has been also combined successfully with various spectroscopic techniques [2, 25, 47]. Among several spectroscopic techniques, Raman spectroscopy on an aqueous solution droplet provides information about the structure and physical properties of the droplet. Therefore, elucidation of the formation and freezing processes of micrometer-sized supercooled aqueous solution droplets in air is the fundamental basis for understanding the physical properties of water at low temperature and, thus, an optical trapping - microspectroscopy study on single aqueous solution droplets at low temperature is worth conducting in detail.

In the present study, we developed a temperature-controlled (198 298 K) laser trapping - microspectroscopy system capable of in situ observations of formation and freezing of single micrometer-sized aqueous solution droplets levitated in air. On the basis of the developed system, we succeeded in laser trapping of single supercooled aqueous ammonium sulfate droplets in air and in situ characterization of the droplets by Raman spectroscopy. Furthermore, we succeeded in direct observation of the freezing event of single micrometer-sized aqueous ammonium sulfate droplets at $213 \mathrm{~K}$. 


\section{Experimental Section}

Water was purified by distillation and deionization prior to use (GSR-200, Advantec Toyo Co., Ltd.). Ammonium sulfate (Wako Pure Chemical Co. Ltd.) was used without further purification. A schematic illustration of the experimental setup used in the present study is shown in Fig. 1. Aerosol water droplets containing ammonium sulfate (1.0 M) were generated by an ultrasonic nebuliser (Omron, NE-U07) and introduced into a sample chamber set on the stage of an inverted optical microscope (Olympus, IX71). A flow of aqueous ammonium sulfate droplets (averaged diameter $\sim 2 \mu \mathrm{m}$ ) in air was introduced into the chamber (internal diameter of $4 \mathrm{~cm}$ and a height of $4 \mathrm{~cm}$ ), and single droplets were trapped by a focused laser beam from a CW-Nd:YVO ${ }_{4}$ laser (532 nm, Coherent, Verdi) through an objective lens $(\times 40, \mathrm{NA}=0.6)$. After trapping a single droplet at $298 \mathrm{~K}$, the flow of aerosol droplets from the nebulizer was stopped. Stable trapping of aqueous ammonium sulfate droplets with the diameter of $5 \sim 20 \mu \mathrm{m}$ was achieved with laser trapping power being $2 \sim 40 \mathrm{~mW}$. The laser beam was simultaneously used as an excitation light source for Raman spectroscopy of single trapped droplets. Raman scattering light from the trapped droplet was collected by the same objective lens and analyzed by a cooled CCD detector (Oriel, InstaspecV) equipped with a polychromator (1200 grooves $/ \mathrm{mm}$ ). Temperature of trapped droplets was controlled $(198 \sim 298 \mathrm{~K})$ by tuning the flow rate $(1 \sim 10 \mathrm{~L} / \mathrm{min})$ of a nitrogen gas 
stream passed through a glass tube dipped in a liquid $\mathrm{N}_{2}$ bath as shown schematically in Fig. 1. In order to prevent condensation of water on the surface of a bottom glass cover slip and minimize the difference in temperature between inside and outside of the chamber, a nitrogen gas cooled with a liquid $\mathrm{N}_{2}$ was also blown against the glass cover slip as shown in Fig. 1. The temperature inside the chamber was monitored by using a thermocouple which was set $\sim 2 \mathrm{~cm}$ above the trapped droplets. By using a CCD camera, we observed morphological changes of single trapped droplets during the experiments.

\section{Results and Discussion}

Noncontact levitation of single aqueous ammonium sulfate droplets in air.

Single micrometer-sized aqueous ammonium sulfate droplets were trapped by a focused laser beam at room temperature (298 K) as shown in Fig. 2. In the present experiments, we used a $532 \mathrm{~nm}$ laser beam as the light source for laser trapping and an aqueous ammonium sulfate solution is transparent at this wavelength. Therefore, temperature elevation of the trapped droplet is not caused by laser irradiation and the droplet shown in Fig. 2A could be levitated stably in several hours. After trapping a single aqueous ammonium sulfate droplet at $298 \mathrm{~K}$, the temperature inside the chamber was controlled by introducing an $\mathrm{N}_{2}$ gas flow into the chamber and the water droplet was cooled with the rate of $0.1 \mathrm{~K} / \mathrm{s}$. The photographs of the trapped water droplet at 298 
$\sim 223 \mathrm{~K}$ are shown in Fig. 2A $\sim$ I. At $298 \mathrm{~K}$, the relative humidity within the chamber was calculated to be $\sim 97 \%$ on the basis of Köhler theory $\left(d=13.7 \mu \mathrm{m}\right.$, $\left[\left(\mathrm{NH}_{4}\right)_{2} \mathrm{SO}_{4}\right]=$ $1.0 \mathrm{M})$ [48]. When the chamber was cooled with the moisture content being kept constant, the size of the droplet gradually increased owing to condensation of water vapor on the trapped droplet as shown in Fig. 2A $\sim$ C. At $273 \sim 253 \mathrm{~K}$, the size of the droplet was almost constant at the diameter $(d)$ of $\sim 20 \mu \mathrm{m}$ as shown in Fig. 2C $\sim$ E. Further cooling of the chamber below $253 \mathrm{~K}$ then gave rise to a gradual decrease in $d$ of the droplet as shown in Fig. $2 \mathrm{~F} \sim \mathrm{I}$. In the present experiments, since we could not control precisely the relative humidity inside the chamber, the decrease in the relative humidity around the droplet below $253 \mathrm{~K}$ would be the reason for vaporization of the droplet and, thus, the decrease in $d$ in Fig. $2 \mathrm{~F} \sim \mathrm{I}$. The results indicate that the equilibrium size of a trapped water droplet is very sensitive to the relative humidity in the chamber and the concentration of a solute (i.e., $\left.\left(\mathrm{NH}_{4}\right)_{2} \mathrm{SO}_{4}\right)$ should be optimized to keep the water vapor pressure in equilibrium under given conditions. The concentration of ammonium sulfate in the trapped water droplet was estimated through the change in the droplet diameter as summarized in Table1.

While the size of the trapped aqueous ammonium sulfate droplet varied in accord with the temperature inside the chamber, the shape of the droplet was always spherical, suggesting that the droplet took a liquid state even at $223 \mathrm{~K}$. In order to confirm this, we 
conducted Raman spectroscopy on single trapped aqueous ammonium sulfate droplets at various temperatures. The Raman spectra observed in the wavenumber region of $2700 \sim$ $4000 \mathrm{~cm}^{-1}$ are shown in Fig. 3. The Raman spectrum observed at $293 \mathrm{~K}$ is characterized by the $\mathrm{OH}$ stretching vibrations of water peaking at $3430 \mathrm{~cm}^{-1}$ with an intense shoulder at $3220 \mathrm{~cm}^{-1}$. The spectral band shapes observed at 293, 273, and $253 \mathrm{~K}$ were very similar to that of liquid water. Below $253 \mathrm{~K}$, two peaks other than the water peaks were appeared at around $2800 \sim 3100 \mathrm{~cm}^{-1}$. Since the concentration of $\left(\mathrm{NH}_{4}\right)_{2} \mathrm{SO}_{4}$ in the droplet increases owing to the decrease in $d$ as seen in Fig. 2F $\sim$ I, the peaks at 2880 and $3090 \mathrm{~cm}^{-1}$ are responsible for $\left(\mathrm{NH}_{4}\right)_{2} \mathrm{SO}_{4}$ in the droplet. In practice, the band at 2880 $\mathrm{cm}^{-1}$ can be assigned to the second overtone of the umbrella bending mode of $\mathrm{NH}_{4}{ }^{+}$and that at $3090 \mathrm{~cm}^{-1}$ is a combination band of the umbrella bending-rocking vibrations (at $\left.\sim 3035 \mathrm{~cm}^{-1}\right)$ and the symmetric stretching vibration $\left(3115 \mathrm{~cm}^{-1}\right)$ of $\mathrm{NH}_{4}{ }^{+}$[49]. It is worth noting that the Raman spectrum of hexagonal ice is best characterized by a sharp and intense band at around $3150 \mathrm{~cm}^{-1}$ responsible for the coupled $\mathrm{OH}$ stretching vibration mode as shown in Fig. 4A. It is clear that a Raman peak responsible for hexagonal ice is not observed in the Raman spectra of the aqueous ammonium sulfate droplets above $223 \mathrm{~K}$ (Fig. 3). These results clearly indicate that the droplet takes a metastable liquid state even at $223 \mathrm{~K}$. 


\section{Freezing of a micrometer-sized aqueous ammonium sulfate droplet in air.}

When an aqueous ammonium sulfate droplet is cooled below $213 \mathrm{~K}$, a supercooled droplet was turned from a liquid to the solid state. A series of snap shots during the freezing processes of the aqueous ammonium sulfate droplet $\left(\left[\left(\mathrm{NH}_{4}\right)_{2} \mathrm{SO}_{4}\right]=3.5 \mathrm{M}\right)$ are shown in Fig. 5: a full movie (Movie S1) is available in supporting information. During laser trapping of the aqueous ammonium sulfate droplet at $213 \mathrm{~K}$, a dark shadow appeared in the droplet (Fig. 5B) and the droplet started vigorous vibrations (Movie S1). A supercooled droplet is levitated in air through radiation force generated by reflection and refraction of incident light by the droplet against gravitational force. However, since the refractive index of the droplet suddenly changes by phase transition, the balance between gravitational force and radiation force experienced by the droplet/ice crystals also vary, leading to droplet/ice crystals vibrations under laser irradiation. Stable laser trapping of the droplet/ice crystals can be achieved by adjusting laser power. After controlling vigorous vibrations of the droplet/ice crystals by laser trapping, the optical microscope observation demonstrated that the morphology of the droplet turned to a golf ball like particle (Fig. 5C). The Raman spectrum of the particle shown in Fig. 5C is displayed in Figure 4B. It is worth noting that a sharp and intense Raman peak was observed at $3150 \mathrm{~cm}^{-1}$. The results demonstrate clearly that the supercooled aqueous ammonium sulfate droplet turned to ice crystals. To the best of our knowledge, this is 
the first observation of the freezing processes of a single micrometer-sized supercooled water droplet in air by means of laser trapping and spectroscopy techniques. The freezing temperature observed in the present experiments falls almost agreed with those reported for water droplets containing $\left(\mathrm{NH}_{4}\right)_{2} \mathrm{SO}_{4}$ ( 38 wt\%) [46]. Furthermore, after freezing of the droplet, water vapor deposits on the ice crystals. The ice crystals grew gradually in size, and its shape deviated from a spherical shape as shown in Fig. 6A $\sim$ C. Because of deviation from a spherical shape (Fig. 6D), the ice crystals fell to the glass cover slip. Further observation of the crystals on the glass plate demonstrated formation of a snowflake (15 min after the freezing). Using a laser trapping technique, an artificial model system corresponding to the initial steps of precipitation in the clouds was constructed successfully under an optical microscope.

\section{Conclusions}

We succeeded in laser trapping of single supercooled aqueous ammonium sulfate droplets in air and in situ characterization of the droplets by Raman spectroscopy. Freezing of a supercooled droplet in air could be observed directly. Furthermore, after freezing, the growth of an ice crystal was observed. In the next step, we are planing to elucidate solute concentration effects on the freezing temperature of aqueous solution 
droplets. Furthermore, it has been predicted theoretically that the freezing temperature of a supercooled water droplet is dependent on the droplet diameter. A further study including droplet size effects on the freezing temperature will reveal detailed physical properties of aerosol water droplets, which is our next target of the study. We convince that the laser trapping-spectroscopy techniques can contribute to the study on microchemistry and microphysics of clouds and precipitation.

\section{Acknowledgements}

S.I. is grateful for the Global COE Program (Project No. B01: Catalysis as the Basis for Innovation in Materials Science) and JST PRESTO Program for partial support of this research. 


\section{References and Notes}

[1] H. Masuhara, F.C. De Schryver, N. Kitamura, N. Tamai, Microchemistry-Spectroscopy and Chemistry in Small Domains, North Holland, Amsterdam, 1994.

[2] N. Kitamura, F. Kitagawa, J. Photochem. Photobiol., C, 4 (2003) 227.

[3] A. Ashkin, J.M. Dziedzic, Science, 187 (1975) 1073.

[4] R. Thurn, W. Kiefer, Appl. Opt., 24 (1985) 1515.

[5] J. Popp, M. Lankers, K. Schaschek, W. Kiefer, J.T. Hodges, App. Opt., 34 (1995) 2380.

[6] J.F. Lubben, B. Schrader, J. Mol. Struct., 410 (1997) 543.

[7] R. Omori, T. Kobayashi, A. Suzuki, Opt. Lett., 22 (1997) 816.

[8] J.F. Lubben, C. Mund, B. Schrader, R. Zellner, J. Mol. Struct., 481 (1999) 311.

[9] C. Mund, R. Zellner, J. Mol. Struct., 661 (2003) 491.

[10] C. Mund, R. Zellner, Chemphyschem, 4 (2003) 630.

[11] C. Mund, R. Zellner, Chemphyschem, 4 (2003) 638.

[12] N. Magome, M.I. Kohira, E. Hayata, S. Mukai, K. Yoshikawa, J. Phys. Chem. B, 107 (2003) 3988.

[13] M.D. King, K.C. Thompson, A.D. Ward, J. Am. Chem. Soc., 126 (2004) 16710.

[14] R.J. Hopkins, L. Mitchem, A.D. Ward, J.P. Reid, Phys. Chem. Chem. Phys., 6 (2004) 4924.

[15] D.R. Burnham, D. McGloin, Opt. Express, 14 (2006) 4175.

[16] N. Jordanov, R. Zellner, Phys. Chem. Chem. Phys., 8 (2006) 2759.

[17] K.J. Knox, J.P. Reid, K.L. Hanford, A.J. Hudson, L. Mitchem, J. Opt. A-Pure Appl. Opt., 9 (2007) S180.

[18] K.J. Knox, J.P. Reid, J. Phys. Chem. A, 112 (2008) 10439.

[19] L. Mitchem, J.P. Reid, Chem. Soc. Rev., 37 (2008) 756.

[20] M. Guillon, K. Dholakia, D. McGloin, Opt. Express, 16 (2008) 7655.

[21] D. McGloin, D.R. Burnham, M.D. Summers, D. Rudd, N. Dewar, S. Anand, Faraday Discuss, 137 (2008) 335.

[22] M.D. Summers, D.R. Burnham, D. McGloin, Opt. Express, 16 (2008) 7739.

[23] G. Hargreaves, N.O.A. Kwamena, Y.H. Zhang, J.R. Butler, S. Rushworth, S.L. Clegg, J.P. Reid, J. Phys. Chem. A, 114 (2010) 1806.

[24] K.J. Knox, D.R. Burnham, L.I. McCann, S.L. Murphy, D. McGloin, J.P. Reid, J. Opt. Soc. Am. B., 27 (2010) 582.

[25] S. Ishizaka, Y. Suzuki, N. Kitamura, Phys. Chem. Chem. Phys., 12 (2010) 9852.

[26] M.B. Baker, T. Peter, Nature, 451 (2008) 299. 
[27] H.R. Pruppacher, J.D. Klett, Microphysics of clouds and precipitation, 2 ed., Kluwer Academic Publishers, Dordrecht, 1997.

[28] J.P.D. Abbatt, S. Benz, D.J. Cziczo, Z. Kanji, U. Lohmann, O. Mohler, Science, 313 (2006) 1770.

[29] S.T. Martin, Geophys. Res. Lett., 25 (1998) 1657.

[30] J.H. Chelf, S.T. Martin, J. Geophys. Res., 106 (2001) 1215.

[31] A. Tabazadeh, O.B. Toon, Geophys. Res. Lett., 25 (1998) 1379.

[32] D.J. Cziczo, J.P.D. Abbatt, J. Geophys. Res., 104 (1999) 13781.

[33] A.J. Prenni, M.E. Wise, S.D. Brooks, M.A. Tolbert, J. Geophys. Res., 106 (2001) 3037.

[34] H.M. Hung, A. Malinowski, S.T. Martin, J. Phys. Chem. A, 106 (2002) 293.

[35] B.H. Larson, B.D. Swanson, J. Phys. Chem. A, 110 (2006) 1907.

[36] B.D. Swanson, J. Atmos. Sci., 66 (2009) 741.

[37] D. Duft, T. Leisner, Atmos. Chem. Phys., 4 (2004) 1997.

[38] B. Kramer, O. Hubner, H. Vortisch, L. Woste, T. Leisner, M. Schwell, E. Ruhl, H. Baumgartel, J. Chem. Phys., 111 (1999) 6521.

[39] H. Vortisch, B. Kramer, I. Weidinger, L. Woste, T. Leisner, M. Schwell, H. Baumgartel, E. Ruhl, Phys. Chem. Chem. Phys., 2 (2000) 1407.

[40] P. Stockel, I.M. Weidinger, H. Baumgartel, T. Leisner, J. Phys. Chem. A, 109 (2005) 2540.

[41] Y.J. Lu, W.J. Xie, B. Wei, Appl. Phys. Lett., 87 (2005) 184017.

[42] Y.J. Lu, B. Wei, J. Chem. Phys., 125 (2006) 144503.

[43] S. Bauerecker, P. Ulbig, V. Buch, L. Vrbka, P. Jungwirth, J. Phys. Chem. C, 112 (2008) 7631.

[44] O.F. Sigurbjornsson, R. Signorell, Phys. Rev. E, 77 (2008) 051601.

[45] T. Koop, B.P. Luo, A. Tsias, T. Peter, Nature, 406 (2000) 611.

[46] D.A. Knopf, M.D. Lopez, Phys. Chem. Chem. Phys., 11 (2009) 8056.

[47] N. Kitamura, M. Yamada, S. Ishizaka, K. Konno, Anal. Chem., 77 (2005) 6055.

[48] H. Köhler, Trans. Faraday Soc., 32 (1936) 1152.

[49] J.L. Dong, X.H. Li, L.J. Zhao, H.S. Xiao, F. Wang, X. Guo, Y.H. Zhang, J. Phys. Chem. B, 111 (2007) 12170. 
Table 1. Concentration of ammonium sulfate in a single aqueous droplet estimated through the change in the droplet diameter $(d)$ in Fig. 2

\begin{tabular}{ccc}
\hline $\mathrm{T} / \mathrm{K}$ & $d / \mu \mathrm{m}$ & {$\left[\left(\mathrm{NH}_{4}\right)_{2} \mathrm{SO}_{4}\right] / \mathrm{M}$} \\
\hline 298 & 13.7 & 1.0 \\
283 & 16.3 & 0.6 \\
273 & 20.0 & 0.3 \\
263 & 20.0 & 0.3 \\
253 & 18.9 & 0.4 \\
248 & 16.8 & 0.5 \\
243 & 10.5 & 2.2 \\
233 & 9.5 & 3.0 \\
223 & 9.0 & 3.5 \\
\hline
\end{tabular}




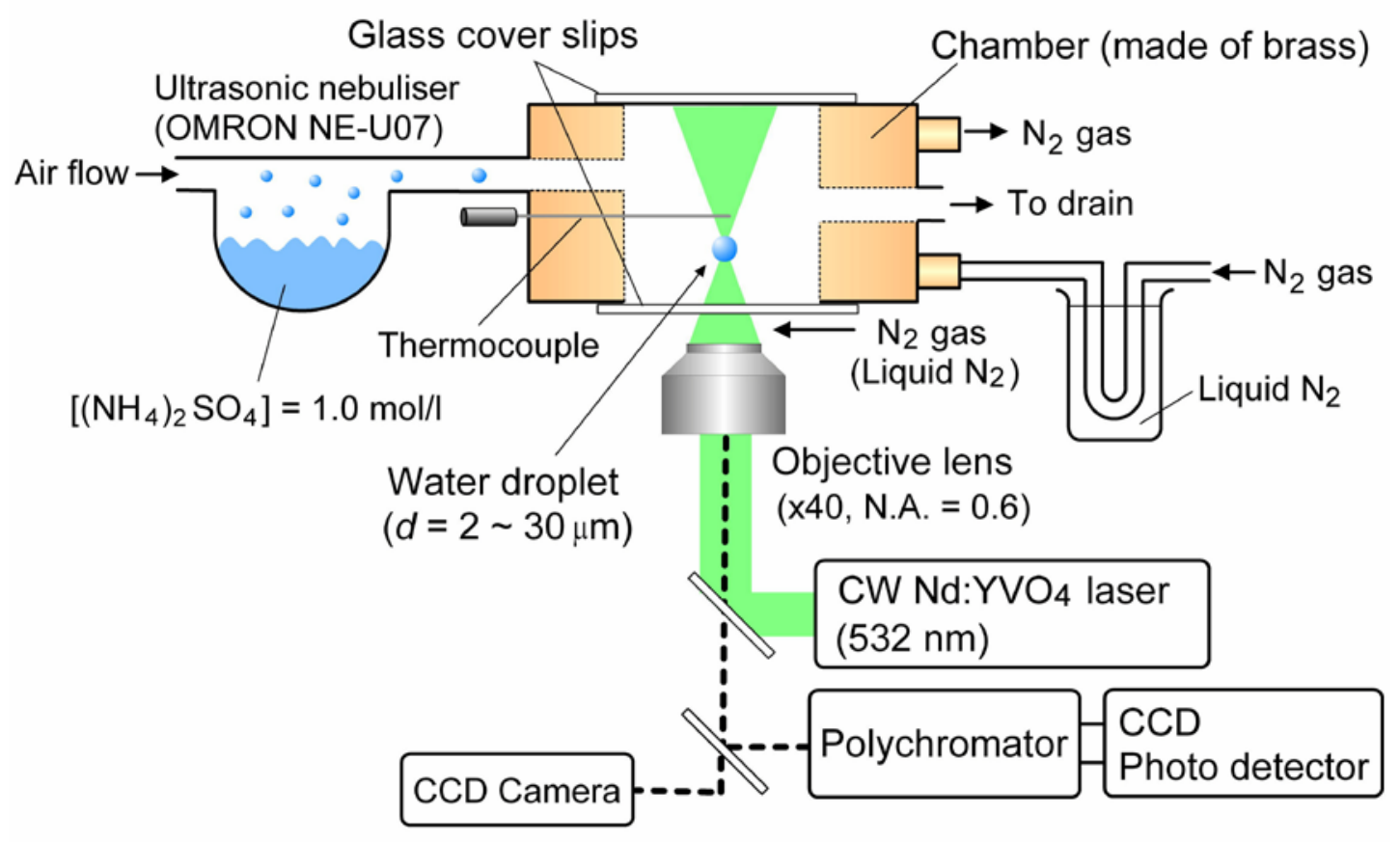

Fig. 1. Schematic illustration of laser trapping and spectroscopic system. 

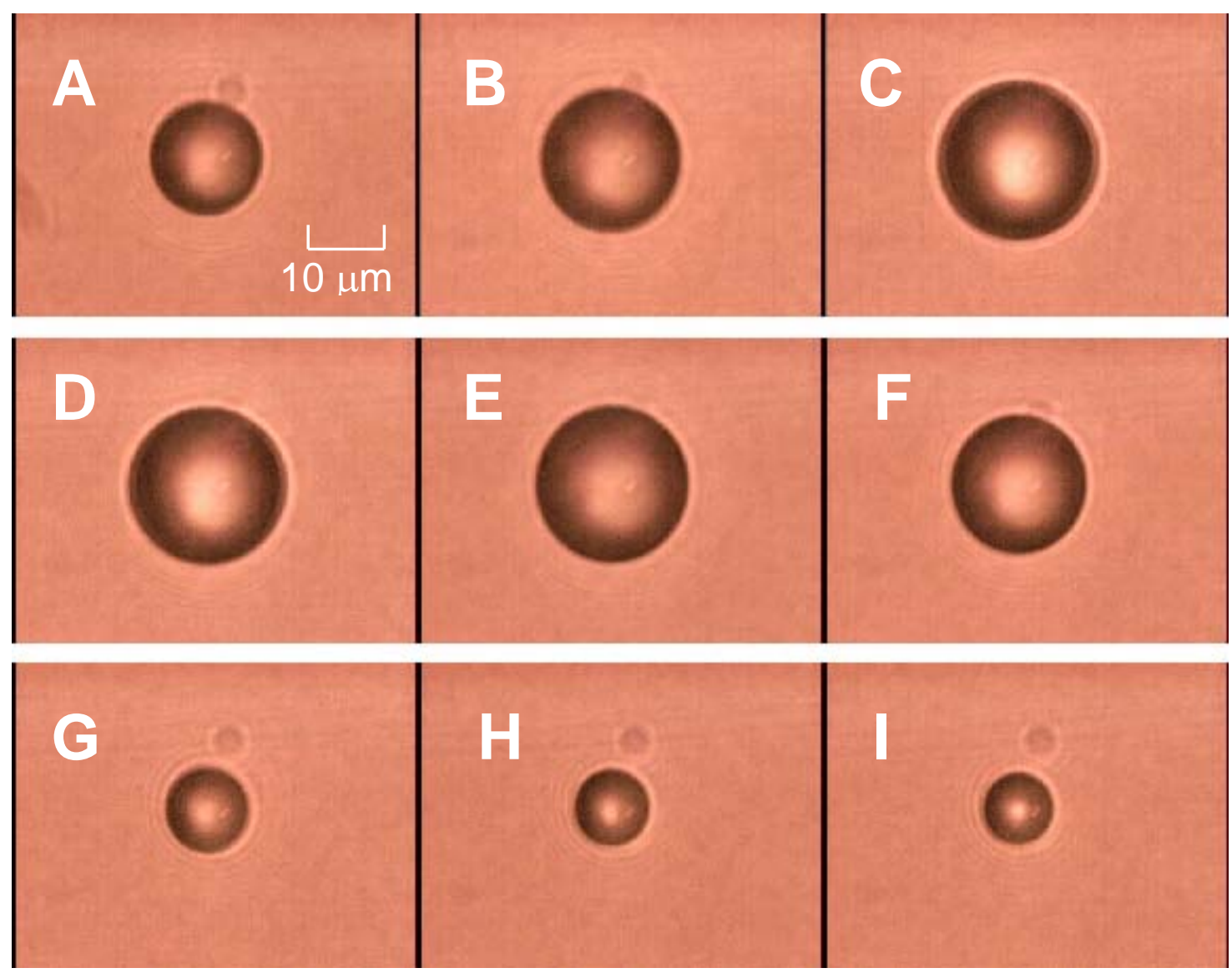

Fig. 2. Pictures of a water droplet levitated in air by means of laser trapping technique at 298 (A), 283 (B), 273 (C), 263 (D), 253 (E), 248 (F), 243 (G), 233 (H) and 223 K (I). 


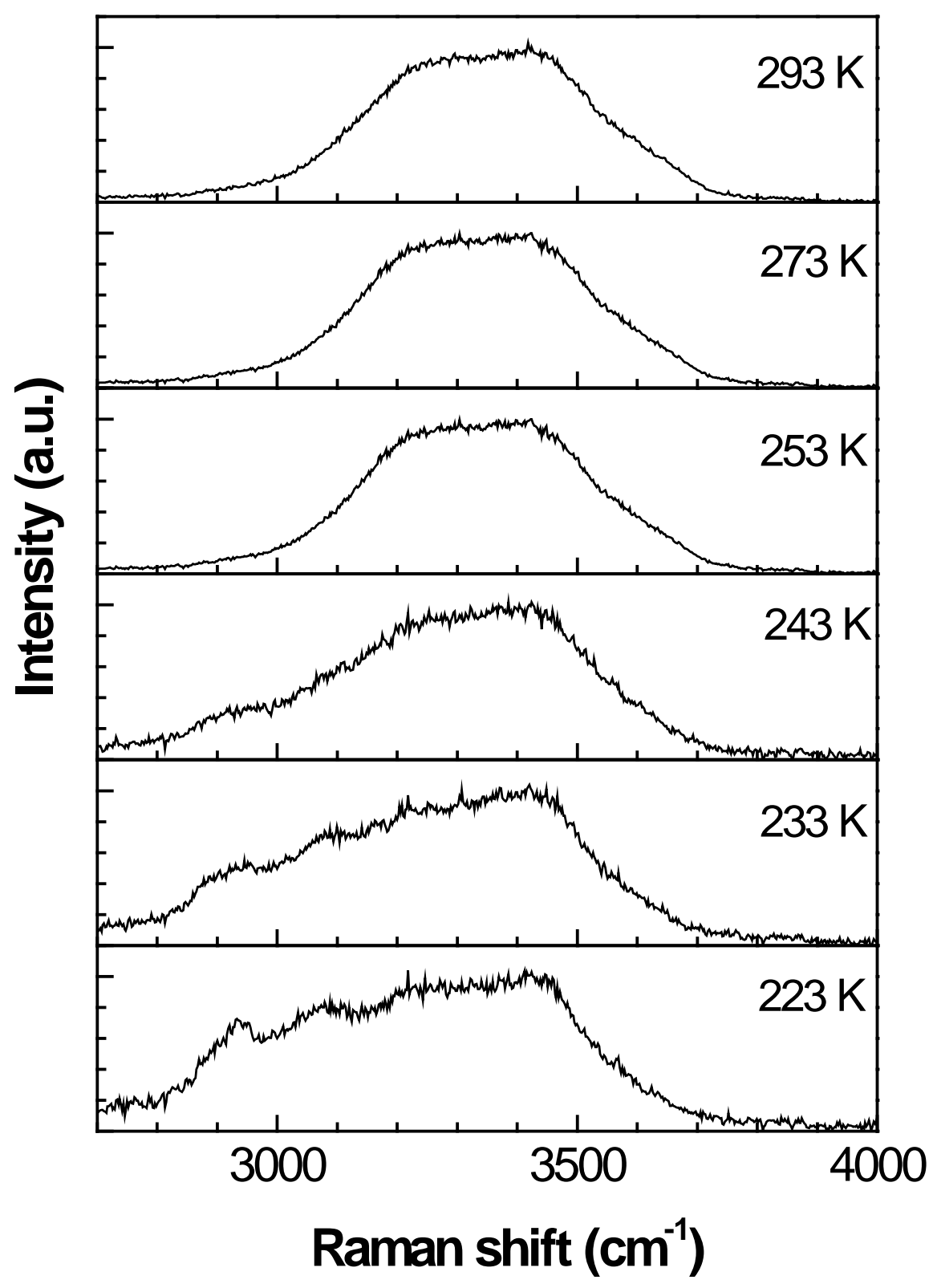

Fig. 3. Temperature dependence of the Raman spectra of a water droplet levitated in air by means of laser trapping technique. 


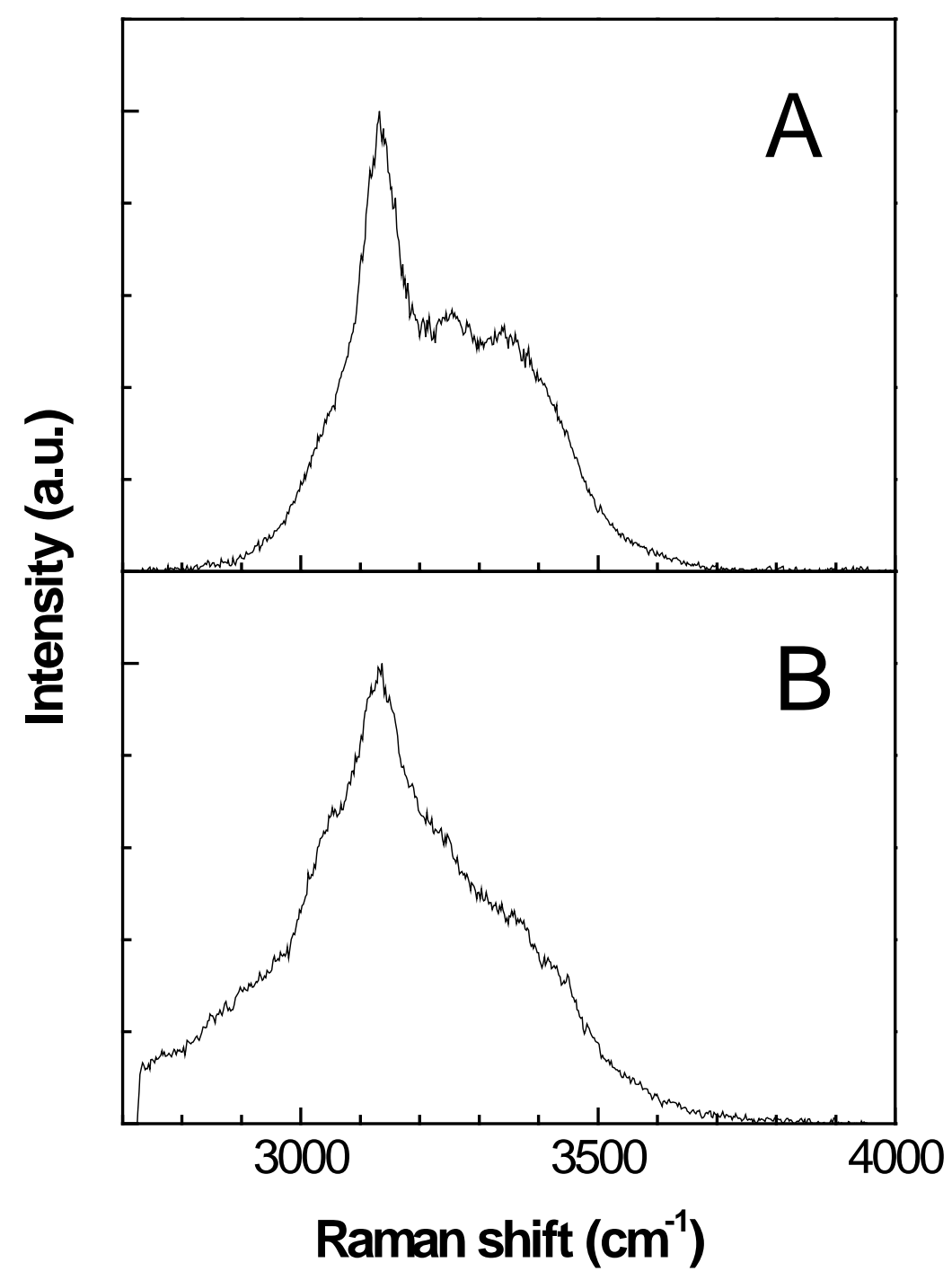

Fig. 4. Raman spectra of hexagonal ice (A) and ice crystals (B). 


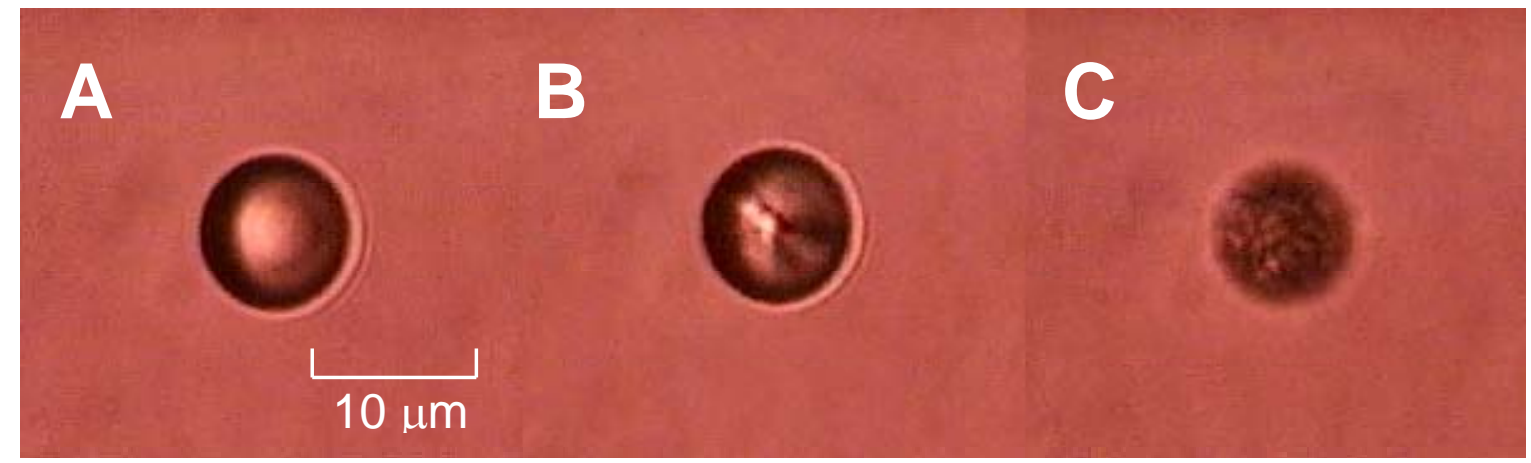

Fig. 5. Sequential video images showing freezing processes of a micrometer-sized aqueous ammonium sulfate droplet $\left(\left[\left(\mathrm{NH}_{4}\right)_{2} \mathrm{SO}_{4}=3.5 \mathrm{M}\right]\right)$ in air at $213 \mathrm{~K}$. 


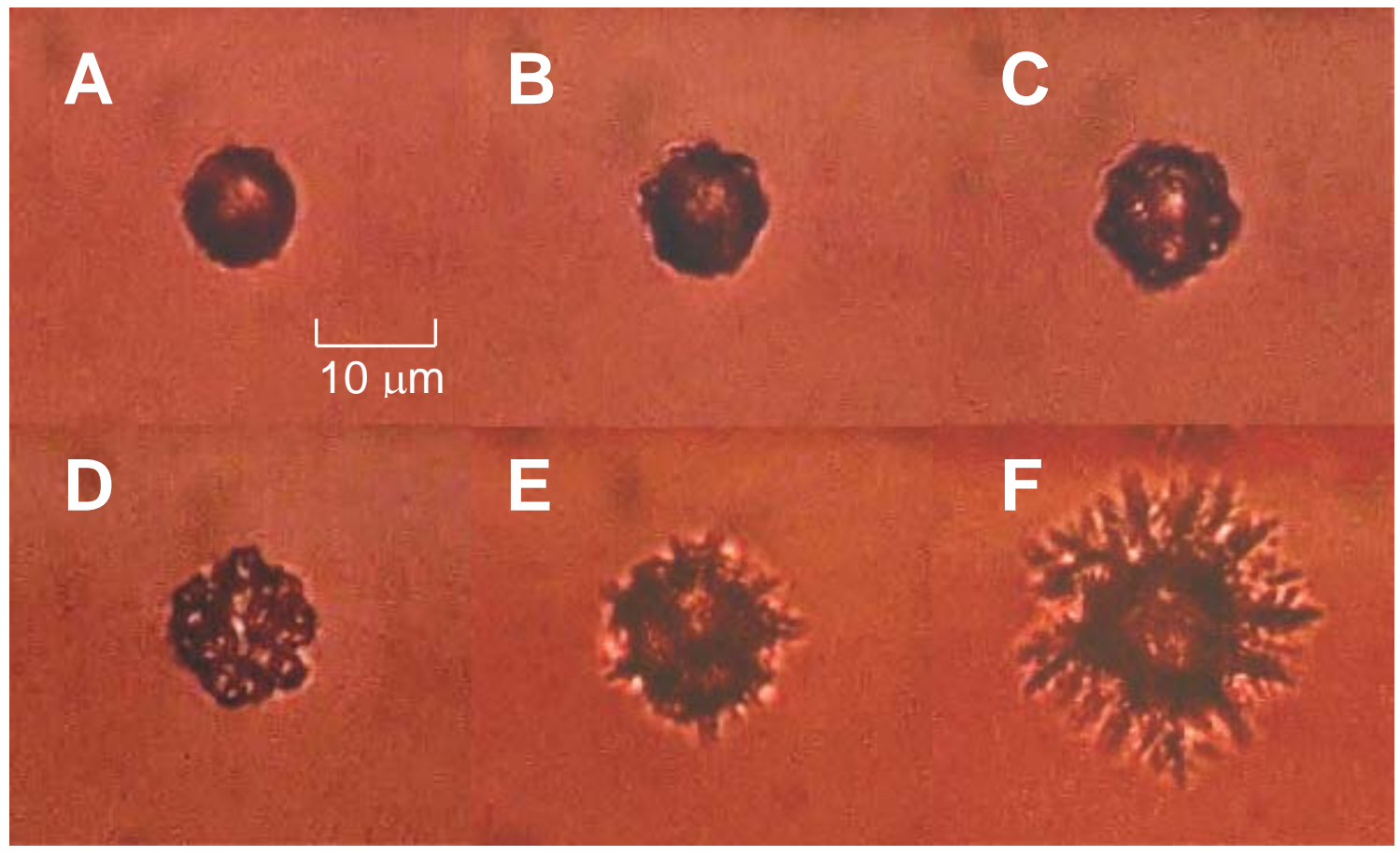

Fig. 6. Growth of ice crystals in air 0 (A), 3 (B), 5 (C), 8 (D), 12 (E) and 15 min. (F) after freezing of a supercooled water droplet. 